\title{
The Role of Social Media Normative Interventions and Environmental Awareness in Intentions to Change Pro-Environmental Behaviors
}

\author{
Anna Vogelaar \\ Rotterdam School of Management \\ Erasmus University \\ vogelaar@rsm.nl
}

\author{
Anna Priante \\ Rotterdam School of Management \\ Erasmus University \\ priante@,rsm.nl
}

\begin{abstract}
Social media interventions to stimulate the adoption of pro-environmental behaviors is a topic of increasing interest in both Information Systems (IS) research and environmental studies. Yet, we still know little about the factors explaining the effectiveness of such interventions and how they influence decision-making in online social networks. By bringing together insights from both social science and IS research streams, this research-inprogress studies intentions to change towards proenvironmental behaviors as the result of exposure to normative social media content and the level of environmental awareness. We conducted an online experiment to explore intentions to change behaviors regarding the consumption of meat. We find that while individual environmental awareness is positively associated with intentions to change meat consumption, exposure to social norms in social media content is not significant in predicting intentions to change meat consumption. Since our findings suggest the importance of environmental awareness in decision-making towards sustainable behaviors, our future research will explore the inclusion of information provision to stimulate environmental awareness in combination with nudging on social media.
\end{abstract}

\section{Introduction}

The study of social media interventions for decision-making and behavioral change towards more sustainable behaviors is a growing area of interest within Information Systems (IS) research [1, 2, 3]. Yet, this stream of research is still in its infancy $[4,5]$. In this in-progress research, we propose to look at social media interventions leveraging social norms as guiding intentions to change behaviors [6]. Recently, socially based information is increasingly used by individuals to make decisions [7]. With the rise of social media, individuals are exposed to a greater diversity of contents compared to traditional media [8, 9]. Building on previous research finding that normative interventions are positively associated with pro-environmental behaviors [e.g. 10, 11, 12], we posit that social media can vehiculate such interventions via exposure to normative content, eventually leading to behavioral change. In addition, we consider the role of individual environmental awareness as an important predictor of proenvironmental behavioral change [13, 14].

Hence, our goal is to study the combined effect of social media content including social norms and environmental awareness in explaining intentions to change towards more pro-environmental behaviors. In this way, we answer recent calls for additional research investigating these two factors together in explaining decision-making in behavior intentions $[15,16]$.

We conduct an experimental study exploring intentions to change behaviors regarding the consumption of meat in the context of a (fictitious) Instagram campaign. Initiating a change in intentions (and ultimately behaviors) to eat less meat is considered key for sustainable development of meat production and consumption, and eventually, climate change $[17,18]$. In particular, social norm interventions on social media, such as Instagram, have been recognized to influence the decision making of individuals in consumption decisions in line with more sustainable behaviors [9, 19].

Our preliminary findings show that while individual environmental awareness is positively associated with intentions to change meat consumption, exposure to social norms in social media content is not significant in predicting intentions. These initial insights provide us with room to further discuss the potential of social media normative interventions and set the ground for our future research, where we will investigate the stimulation of environmental awareness through information provision combined with interventions in the social media context.

This paper is structured as follows. First, we introduce the key concepts of this study, review 
previous work on the topic and present the hypotheses of our study. Then, we describe the study design and analytical approach. Next, we describe and discuss our findings, before presenting our contributions, limitations of the study and venues for future research.

\section{Theory and hypothesis}

\subsection{Social norms and social media interventions}

The theoretical developments to understand and predict behavioral intentions have largely been promoted by the Theory of Reasoned Action [20,21], which builds upon the well-known Theory of Planned Behavior [22]. The supporters of this theory propose that the decision to perform a certain behavior is dependent on the norms and attitudes towards the given behavior [22]. Social norms are "rules or standards that are understood by members of a group, and that guide and/or constrain social behavior without the force of law" [6, p.152]. In other words, social norms are predictors of behavioral intentions as they shape the perceptions of an individual to perform a certain behavior $[22,23,24,25]$. In particular, behavioral intentions can be altered by changing the normative beliefs towards a particular behavior, making normative interventions an ideal path towards stimulating individuals to perform such a behavior [23]. Social norms can be descriptive or injunctive: While descriptive norms indicate perceptions of which behavior is typically prevalent, injunctive norms involve the perceptions of which behavior is typically approved or disapproved [26].

Past research finds that exposure to social norms in the form of normative interventions increases the intentions and, eventually, decisions to adopt proenvironmental behaviors [10, 11, 12, 23]. For instance, a field experiment illustrates that exposure to energy consumption of participants' neighbors had reduced their own consumption by $2 \%$ compared to the control group with no normative information [27]. In addition, in a study about pro- environmental behaviors in the touristic industry

[12] show that exposing people to descriptive norms illustrating the rate of towel reuse in hotel rooms to reduce water consumption positively affects people's decision to reuse towels themselves. More specifically, [11] investigate differences between descriptive and injunctive normative interventions in situations where new sustainable products are promoted, and find that the use of descriptivenorms results in a higher intention to consume sustainable product compared to injunctive normative interventions. Similar results are found in research investigating pro-environmental behaviors in the context of green communication [26], littering [28], and recycling [29].

Recently, social norm interventions have been increasingly applied to the context of social mediabased interventions and decision-making [9, 30, 31]. Studies find that exposure to content in social media consolidates values and actions for proenvironmental behavior $[32,33,34]$. This is facilitated by the informality [35] and high level of anonymity in social media, leading to greater adherence to the displayed norms [36]. Moreover, the context of social media is considered ideal for the experimentation with social norms, as optimizations of the interventions can be done in real-time [37] and effects can be seen more rapidly [9]. This is due to the so-called 'Crescendo Effect', which accelerates the decision process of individuals due to their involvement with socially based information [9]. Yet, we still know little about the effectiveness of such social media normative interventions in explaining the intention to change towards more proenvironmental behavior.

In this study, we look at exposure to social media content showcasing descriptive norms, as descriptive norms are more effective in decisionmaking towards pro-environmental behaviors $[26$, $28,29]$. More specifically, in line with recent calls [38], we investigate the effect of both descriptive prescriptive norms (i.e., what people do) and proscriptive descriptive norms (what people do not do) in explaining intentions to change towards proenvironmental behaviors. [39] expose participants to both do's- (i.e., prescriptive norms) and don'ts' (i.e., proscriptive norms) about sustainable consumptions and find that these normative interventions influence the decision to adopt a more sustainable food consumption.

As an example of pro-environmental behavior change, we focus on the issue of overconsumption of meat. The increasing global production, transportation and consumption of meat contributes to $15 \%$ of the global anthropogenic greenhouse gas emissions [40]. However, while meat alternatives have increasingly become available [41], adoption rates for these products have been rather low [42]. Hence, this research-in-progress sets out to test whether (descriptive) prescriptive and proscriptive norms have an influence on behavioral intentions towards changing meat consumption. In line with past research [39, 43], we posit that both (descriptive) social norms have a positive influence on intentions change. Hence, 
H1.1: The exposure to proscriptive (descriptive) social norms in social media content positively

influences the intentions to change meat consumption.

H1.2: The exposure to prescriptive (descriptive) social norms in social media content positively influences the intentions to change meat consumption.

\subsection{Environmental awareness and pro- environmental behavioral intentions}

Environmental awareness refers to the attitudes towards and the extent to which an individual is aware of the endangered environment [44]. A meta- analysis [13] highlights that environmental awareness is one of the most important factors explaining proenvironmental behavior and often it represents the main, direct predictor [45]. People with high environmental awareness show a more positive attitude towards pro-environmental behavior and are more likely to change their behavioral intentions towards the given behavior regarding sustainable food consumption [46], recycling [16], and engagement in societal relevant activities [47]. More generally, increased environmental awareness drives individual's intention and final decision-making to reduce consumption of goods and services to a more sustainable level [48]. Hence, we posit that the same assumption is valid for changing meat consumption towards meat alternatives. More formally,

$\mathrm{H} 2$ : The higher the environmental awareness, the higher the intention to change meat consumption.

\subsection{The interaction effect between exposure to social norms in social media content and environmental awareness}

Previous research finds that social norms and environmental awareness are both driving intention to adopt pro-environmental behaviors, such as recycling [16], alcohol reduction [49], sustainable energy consumption [50], and green travelling [15, 51]. With regards to food consumption, it has been found that healthy eating intentions are higher for individuals who, next to having a high environmental awareness, are also highly influenced by exposure to social norms $[52,53]$.

We posit that this is also the case for exposure to social norms in social media content. Research finds that individuals who hold high environmental awareness also have greater concern for social media content which includes pro-environmental behavior $[54,55]$. Hence, we posit that having a high environmental awareness strengthens the effect of exposure to both proscriptive and prescriptive normative content in social media. More specifically,

H3.1: The higher the individual environmental awareness, the stronger the association between exposure to proscriptive (descriptive) social norms in social media content and the intention to change meat consumption.

H3.2: The higher the individual environmental awareness, the stronger the association between exposure to proscriptive (descriptive) social norms in social media content and intentions to change meat consumption.

\section{Methods}

Study design. We conducted an online experiment using an existing Instagram campaign initiated by a meat-alternative company. Instagram is a social media platform that allows users to share pictures, videos, and stories with their followers. We chose to focus on Instagram for two reasons. First, with over 1 billion active users per month, Instagram belongs to one of the most used social platforms. Second, previous research shows that exposure to behavior and opinions is facilitated via visual content [56]. Hence, Instagram represents an ideal setting because of its primary focus on visual content compared to other social media platforms, such as Facebook or Twitter.

Participants for the experiment were recruited using Prolific, an online crowdsourcing platform for academic studies. The experimental setting was created using the online survey software Qualtrics. At the beginning of the experiment, participants were provided with a short introduction to the study and then randomly assigned to one of the 7 conditions of the study to test our Hypotheses (Table $1)$.

Table 1. Overview Experimental Conditions

\begin{tabular}{lll}
\hline Condition & Proscriptive Norm & Prescriptive Norm \\
\hline 1 & & \\
2 & & \\
3 & & \\
4 & & \\
5 & & \\
6 & & \\
7 & & \\
\hline
\end{tabular}


We adopted and manipulated images and captions from the campaign to design the conditions (see Appendix 1 for an overview of the images used in each of the seven conditions). An attention check was included to reflect the difference between the showcased behavior of eating a meat alternative product and only displaying the product. This is in line with past literature showing that social media content including the performance of the behavior at hand reflected a (descriptive) social norm [56]. The manipulation checks confirmed the successful manipulation of the normative interventions. Condition 1 was used as a control group, where only the behavior of eating the meat product was shown. Condition 2-7 were used for the social norm interventions. Based on [39], we replaced the images' captions to design the interventions: "Please eat meat alternatives" describes the prescriptive condition (i.e., what the participant should do), while "Don't eat meat" is the proscriptive condition (i.e., what participants should not do).

In addition, we controlled for the effect of existing comments in the pictures. Research shows that comments can be of normative nature, as individuals are fundamentally driven to compare themselves to others [57]. We included existing comments taken from the Instagram page of the meat alternative company. Conditions $4 \& 5$ show aligned comments, while conditions $6 \& 7$ show misaligned comments. In writing the comments, we use examples based on previous research $[58,59,60]$ and drafted normative aligned comments using primarily adjectives and misaligned comments using mostly verbs, as in [61]. In this way, we control for both aligned and controversial opinions that can influence decisionmaking in the social media context, as found in the literature [62].

After being exposed to the social media post (based on the randomly assigned condition), participants were asked to rate their intentions to change meat consumption using a 7-point Likert scale from 1 (strongly disagree) to 7 (strongly agree). In line with past research capturing behavioral intentions $[23,56]$, we used the statement "I intend to change my meat consumption by reducing or eating meat alternatives within the next 3 months.". From these conditions, we derived the measure of prescriptive and proscriptive social norm interventions (both variables treated as dichotomous, yes $=1$ ).

Finally, participants completed a short survey from which we derived measures of their level of environmental awareness, socio-demographic information and other controls (i.e., age, gender, nationality, education, level of Instagram usage and whether the diet was restricted to meat consumption).
To test H2, environmental awareness was measured using seven statements, adjusted from the New Environmental Paradigm (NEP) [63]. ${ }^{1}$ We constructed the overall mean score of environmental awareness [64] and created a classification into high and low environmental awareness [65].

Participants. Overall, we collected 269 valid responses. The mean age was 26 years (ranging from 18 to 61). Participants were equally distributed by gender (females $=50.97 \%$ ). The highest education achieved by participants was High School $(47.49 \%)$, followed by Bachelor's degree $(33.59 \%)$ and Master's degree (17.37\%). Most of the participants used Instagram daily (65.64\%) and did not restrict their meat consumption $(66.80 \%)$.

Analytical approach. As our dependent variable is ordinal, we used ordinal logistic regression in Stata 16 to test our hypotheses. Assumptions for ordinal regression were checked and valid. No multicollinearity issue was detected, as confirmed by the Variance Inflation Factor analysis. All these additional analyses are available upon request.

\section{Results}

Table 2 shows the results of the ordinal logistic regression, while Table 3 illustrate an overview of our hypotheses and related findings. Model 1 is the baseline model with the dependent variable and the controls. Model 2 adds the independent variable of social norms to test H1.1 and H1.2. We expected that the inclusion of social norms in social media content would result in a higher intention to change meat consumption as compared to non-normative content. However, we do not find a significant effect, thus rejecting both $\mathrm{H} 1.1$ and H1.2. Model 3 adds the independent variable of environmental awareness to test whether it has an effect on the intentions to change meat consumption (H2). Model 3 shows that a higher mean of environmental intention increases the odds of a positive effect on the intentions to change meat consumption, with all controls held constant. Thus, H2 is supported. Model 4 includes both independent variables into a full model and shows that the effects found in Model 1 and Model 2 are consistent. Last, Model 5 includes the interaction term of the independent variables to test H3.1 and H3.2. Although not significant, the coefficients for prescriptive and proscriptive norms have changed in comparison to the control conditions. While the proscriptive condition still results in a lower intention to change meat consumption than the non-normative content, the prescriptive norm results in a higher intention to change meat consumption than the 
control conditions. We found evidence of this at the bivariate level, where a Kruskal-Wallis H Test was conducted and a post-hoc test revealed that there is a significant difference $(\beta=-1.810, p=0.035)$. More information available upon request. Yet, these effects are not significant in the regression model, thus we reject both H3.1 and H3.2.

Table 2. Ordered logistic regression.

\begin{tabular}{|c|c|c|c|c|c|c|c|c|c|c|c|c|c|c|c|}
\hline Variable & \multicolumn{3}{|c|}{ Model 1} & \multicolumn{3}{|c|}{ Model 2} & \multicolumn{3}{|c|}{ Model 3} & \multicolumn{3}{|c|}{ Model 4} & \multicolumn{3}{|c|}{ Model 5} \\
\hline Intentions & $\mathrm{b}$ & SD & $\mathrm{p}$ & $\mathrm{b}$ & SD & $\mathrm{p}$ & $\mathrm{b}$ & SD & $\mathrm{p}$ & $\mathrm{b}$ & SD & $\mathrm{p}$ & $\mathrm{b}$ & SD & $\mathrm{p}$ \\
\hline $\begin{array}{c}\text { Social Norms } \\
\text { Proscriptive } \\
\text { Prescriptive }\end{array}$ & & & & $\begin{array}{l}-0.303 \\
-0.071 \\
\end{array}$ & $\begin{array}{l}0.392 \\
0.382\end{array}$ & $\begin{array}{l}0.439 \\
0.853\end{array}$ & & & & $\begin{array}{l}-0.263 \\
-0.133 \\
\end{array}$ & $\begin{array}{l}0.395 \\
0.380 \\
\end{array}$ & $\begin{array}{l}0.505 \\
0.727\end{array}$ & $\begin{array}{c}0.654 \\
-1.830 \\
\end{array}$ & $\begin{array}{l}1.976 \\
2.034 \\
\end{array}$ & $\begin{array}{l}0.741 \\
0.368\end{array}$ \\
\hline $\begin{array}{l}\text { Environmental } \\
\text { Awareness }\end{array}$ & & & & & & & 0.838 & 0.160 & $0.000^{* 4 *}$ & 0.832 & 0.160 & $0.000^{* 4+4}$ & 0.794 & 0.319 & $0.011^{*}$ \\
\hline $\begin{array}{l}\text { Social Norm } \\
\text { 'Environmental } \\
\text { Awareness }\end{array}$ & & & & & & & & & & & & & $\begin{array}{c}-0.192 \\
0.339 \\
\end{array}$ & $\begin{array}{l}0.390 \\
0.397 \\
\end{array}$ & $\begin{array}{l}0.620 \\
0.393 \\
\end{array}$ \\
\hline Diet & & & & & & & & & & & & & & & \\
\hline $\begin{array}{l}\text { Restricted (a) } \\
\text { Restricted (b) }\end{array}$ & $\begin{array}{l}-1.431 \\
-4.354\end{array}$ & $\begin{array}{l}0.528 \\
0.937\end{array}$ & $\begin{array}{l}0.007^{* 4} \\
0.000^{* 4 *}\end{array}$ & $\begin{array}{l}-1.438 \\
-4.467\end{array}$ & $\begin{array}{l}0.531 \\
0.950\end{array}$ & $\begin{array}{c}0.007^{* *} \\
0.000^{* * *}\end{array}$ & $\begin{array}{l}-1.391 \\
-3.945\end{array}$ & $\begin{array}{l}0.539 \\
0.947\end{array}$ & $\begin{array}{l}0.010^{* 4} \\
0.000^{* 4+}\end{array}$ & $\begin{array}{l}-1.411 \\
-4.053\end{array}$ & $\begin{array}{l}0.542 \\
0.961\end{array}$ & $\begin{array}{l}0.009^{4 *} \\
0.000^{* 4 *}\end{array}$ & $\begin{array}{l}-1.413 \\
-3.981\end{array}$ & $\begin{array}{l}0.547 \\
0.963\end{array}$ & $\begin{array}{l}0.010^{* * *} \\
0.000^{* * *}\end{array}$ \\
\hline Not restricted & -4.114 & 0.554 & $0.000^{* 4+4}$ & -4.096 & 0.559 & $0.000^{* 4+4}$ & -4.038 & 0.565 & $0.000^{4+4}$ & -4.057 & 0.569 & $0.000^{* 4+4}$ & -4.054 & 0.572 & $0.000^{* 4 *}$ \\
\hline Gender & 0.320 & 0.252 & 0.205 & 0.308 & 0.254 & 0.227 & 0.199 & 0.256 & 0.438 & 0.183 & 0.258 & 0.478 & 0.194 & 0.259 & 0.455 \\
\hline $\begin{array}{l}\text { Education } \\
\text { High School }\end{array}$ & 0.278 & 1.115 & 0.803 & 0.428 & 1.127 & 0.704 & 0.223 & 1.130 & 0.843 & 0.309 & & 0.787 & 0.157 & 1.149 & 0.892 \\
\hline Bachelor & 0.740 & 1.130 & 0.513 & 0.859 & $\begin{array}{l}1.127 \\
1.138\end{array}$ & 0.450 & 0.506 & $\begin{array}{l}1.130 \\
1.135\end{array}$ & $\begin{array}{l}0.843 \\
0.659\end{array}$ & 0.578 & $\begin{array}{l}1.142 \\
1.153\end{array}$ & $\begin{array}{l}0.787 \\
0.161\end{array}$ & $\begin{array}{l}0.157 \\
0.441\end{array}$ & $\begin{array}{l}1.149 \\
1.160\end{array}$ & $\begin{array}{l}0.892 \\
0.704\end{array}$ \\
\hline Master & 0.973 & 1.150 & 0.398 & 1.094 & 1.157 & 0.344 & 0.831 & 1.164 & 0.476 & 0.901 & 1.172 & 0.442 & 0.801 & 1.178 & 0.496 \\
\hline Doctoral & 0.528 & 1.999 & 0.792 & 0.522 & 2.010 & 0.795 & -0.266 & 2.301 & 0.908 & -0.287 & 2.296 & 0.901 & -0.579 & 2.414 & 0.811 \\
\hline Age & -0.458 & 0.481 & 0.341 & -0.380 & 0.486 & 0.434 & -0.248 & 0.487 & 0.610 & -0.203 & 0.490 & 0.478 & -0.189 & 0.491 & 0.700 \\
\hline Instagram Use & & & & & & & & & & & & & & & \\
\hline Monthly & 0.555 & 0.951 & 0.560 & 0.586 & 0.956 & 0.536 & 1.089 & 1.033 & 0.292 & 1.127 & 1.028 & 0.273 & 1.294 & 1.038 & 0.213 \\
\hline Weekly & 0.610 & 0.888 & 0.492 & 0.643 & 0.884 & 0.466 & 1.080 & 0.973 & 0.267 & 1.111 & 0.968 & 0.251 & 1.137 & 0.969 & 0.241 \\
\hline Daily & 0.842 & 0.854 & 0.324 & 0.856 & 0.850 & 0.314 & 1.331 & 0.944 & 0.158 & 1.356 & 0.938 & 0.148 & 1.411 & 0.941 & 0.133 \\
\hline Hourly & 1.094 & 0.929 & 0.239 & 1.175 & 0.928 & 0.205 & 1.634 & 1.013 & 0.107 & 1.700 & 1.011 & 0.093 & 1.772 & 1.011 & 0.080 \\
\hline Comment & & & & & & & & & & & & & & & \\
\hline Unaligned & -0.133 & 0.298 & 0.655 & -0.152 & 0.299 & 0.611 & -0.162 & 0.302 & 0.592 & -0.173 & 0.303 & 0.567 & -0.189 & 0.303 & 0.534 \\
\hline No comment & 0.047 & 0.275 & 0.865 & 0.058 & 0.33 & 0.861 & -0.042 & 0.279 & 0.879 & -0.144 & 0.330 & 0.663 & -0.147 & 0.330 & 0.655 \\
\hline Pseudo $R$ & \multicolumn{3}{|c|}{0.1495} & \multicolumn{3}{|c|}{0.1495} & \multicolumn{3}{|c|}{0.1788} & \multicolumn{3}{|c|}{0.1793} & \multicolumn{3}{|c|}{0.1818} \\
\hline Model $D$ & \multicolumn{3}{|c|}{0.0000} & \multicolumn{3}{|c|}{0.0000} & \multicolumn{3}{|c|}{0.0000} & \multicolumn{3}{|c|}{0.0000} & \multicolumn{3}{|c|}{0,0000} \\
\hline
\end{tabular}

Table 3. Overview of hypotheses and results.

\begin{tabular}{|l|l|l|}
\hline Hypothesis & Result \\
\hline H1.1 & $\begin{array}{l}\text { The exposure to proscriptive } \\
\text { (descriptive) social norms in social } \\
\text { media content positively influences } \\
\text { the intentions to change meat } \\
\text { consumption. }\end{array}$ & Rejected \\
\hline H1.2 & $\begin{array}{l}\text { The exposure to prescriptive } \\
\text { (descriptive) social norms in social } \\
\text { media content positively influences } \\
\text { the intentions to change meat } \\
\text { consumption. }\end{array}$ & Rejected \\
\hline H2 & $\begin{array}{l}\text { The higher the environmental } \\
\text { awareness, the higher the intention } \\
\text { to change meat consumption. }\end{array}$ & Accepted \\
\hline H3.1 & $\begin{array}{l}\text { The higher the individual } \\
\text { environmental awareness, the } \\
\text { stronger the association between } \\
\text { exposure to proscriptive } \\
\text { (descriptive) social norms in social } \\
\text { media content and the intention to } \\
\text { change meat consumption. }\end{array}$ & Rejected \\
\hline H3.2 & $\begin{array}{l}\text { The higher the individual } \\
\text { environmental awareness, the } \\
\text { stronger the association between } \\
\text { exposure to proscriptive } \\
\text { (descriptive) social norms in social } \\
\text { media content and intentions to } \\
\text { change meat consumption. }\end{array}$ & \\
\hline \multicolumn{1}{|c|}{ Rejected } \\
\hline
\end{tabular}

\section{Discussion}

Pro-environmental behavioral intention change can be stimulated via social media normative interventions. Building on previous research finding that environmental awareness $[66,67]$ and normative interventions influence pro- environmental behavioral intentions $[10,11,12]$, we expand this area of investigation to the context of social media. We hypothesized that exposure to social norms and individual environmental awareness have a positive effect on the intentions to behave more proenvironmentally. While we found a positive, significant effect of environmental awareness on proenvironmental behavioral intentions, such as change in meat consumption in line with 46 and 48 , we could not find support for the effect of social norms interventions on intention to change meat consumption. We outline two possible explanations. First, one of the risks of exposure to normative content in social media is that it simultaneously presents the issue and attempts to correct it [68]. We argue that a possible solution is to focus on the relevance of issue rather on its correction. Previous research shows that when interventions in the relevant behavioral setting make the norm more salient and focused, such interventions are more effective on behavioral intentions and, eventually, the decision to change 
behavior [69]. Hence, we propose to link normative social media content to stimuli that are likely present in the relevant setting when the intervention occurs (i.e., social media). In this way, when individuals come across such stimuli, they are offered with cues that focus on the relevant normative information [68]. Second, the insignificant effect of social norms interventions on intention to change meat consumption might be related to the perception of food consumption as linked to habits, routines or personal preferences - and not only to social comparison or normative pressure [31]. In other words, habits and routines might act as barriers to change meat consumption [70, 71]. In this vein, [72] argue that the effectiveness of interventions is influenced by the strengths of preferences and the degree to which the food choice at hand is habitual. This, in fact, can be decisive in explaining decisionmaking in adopting such behaviors. Hence, perceived behavior control might have a direct effect on the intentions to change meat consumption, while also moderating the relationship with social norms towards the intentions to change meat consumption $[23,25]$.

Last, in contrast to our expectations, we did not find an interaction effect between social norms and environmental awareness. One possible explanation could be that environmental awareness might interact with social normative context when choices are offered [21]. Social media campaigns promoting pro-environmental behaviors often focus (only) on the target (pro-environmental) behavior as a "nochoice' situation. In situations in which individuals need to decide between two options, they tend to behave solely based on their decision on attitudes and norms towards the alternative alone. Hence, social media content might need to reflect a choice situation in which people are given the possibility to choose among options, for instance, between two products of which one is more sustainable than the other. In addition, building on our finding of the positive, significant effect of environmental awareness, we argue that social media intervention should provide information about the level of environmental impact of the products as a nudge in social media normative interventions, so to stimulate decision-making in adopting these behaviors [73]. This is in line with recent developments in behavioral economics showing that the use of social norms as informing people of what others do and what "most people think people should do" is a powerful driver of decision-making in behavioral contexts [74, p. 63]. However, the inclusion of environmental awareness into the social media content needs to be carefully considered. For instance, country differences as well as political orientation need to be considered [5] when employing normative interventions. In addition, the source of the content needs to be considered as it might have an influence on the credibility of the normative source [75].

\section{Conclusions}

In this paper, we study social media interventions to stimulate the adoption of pro- environmental behaviors as the results of exposure to normative social media content and individual level of environmental awareness. We found that while individual environmental awareness is positively associated with intentions to change meat consumption, exposure to social norms in social media content is not significant in predicting intentions to change meat consumption. Similarly, we found no interaction effect between environmental awareness and social norm.

Some limitations of our study need to be addressed. First, our study investigates intentions to change meat consumption and not the actual decisionmaking process. While our focus is primarily on behavioral intentions, future research could investigate normative interventions about changing meat consumption in a concrete behavioral setting. In this vein, adopting a longitudinal approach can help tracking the actual decision- making process and the normative intervention effect over time. Second, this study might be affected by the so-called social media population bias [76] as our findings' generalizability is limited to the Instagram population. Hence, future studies can try to test our hypotheses using other social media platforms. Third, while we controlled for the normative effects of aligned vs misaligned content in social media comments, more research is needed to assess moderating social comparison or social pressure effects influencing behavioral intentions and, eventually, decisions to adopt behaviors [57]. Last, we did not consider the boomerang effect when exposing the respondents to the social norm interventions. [68] illustrate that through the boomerang effect, individuals amplify their negative behaviors towards the social norm. Thus, due to its effect on the decision-making process of individuals, this notion needs to be furtherexplored.

Despite its in-progress nature and limitations, our study already provides some important implications for theory and practice. On the one hand, we contribute to social media research within the IS field by answering to existing calls $[2,3,77$, $78]$ to deepen our understanding of the application of social media to pro-environmental behavioral intentions. We provide initial insights about the potential of social media use for normative 
interventions, in particular in support of proenvironmental behaviors. Practically, our preliminary results can already inform the design of social media interventions promoting proenvironmental behavioral changes. In particular, we believe that such interventions on social media connect both the social science and IS fields more deeply to practice. We propose to take an interdisciplinary approach that links research with a societal impact by connecting the creation of knowledge with practical applications fostering for social change [76], such as sustainable development and pro-environmental behaviors.

Based on our findings and discussion, our future research will include social media content that better links to relevant setting stimuli as well as to "choice situations'. In addition, as our findings suggest the importance of environmental awareness in decisionmaking towards sustainable behaviors, we will explore the inclusion of information provision to stimulate environmental awareness in combination with nudging on social media.

\section{References}

[1] Liu, X., Zhang, B., Susarlia, A., Padman, R. (2020). Go to You Tube and Call Me in the Morning: Use of Social Media for Chronic Conditions. MIS Quarterly, 44(1), 257283.

[2] Warren, A. M., Sulaiman, A., Jaafer, N. I. (2015). Understanding civic engagement behavior on Facebook from a social capital theory perspective. Behav. Inf. Technology. 34(2), 163-175.

[3] Zhang, W., Johnson, T. J., Seltzer, T., Bichard, S. L. (2010). The Revolution will be Networked the Influence of Social Networking Sites on Political Attitudes and Behavior. Social Science Computer Review. 28(1), 75- 92.

[4] Liu, C.-W., Gao, G., Agarwal, R. (2019). Unraveling the "Social" in Social Norms: The Conditioning Effect of User Connectivity. Information Systems Research. 30(4), 12721295.

[5] Yasmin, P., Fei, M., Lahlou, S., Levy, S. (2019). Using Social Norms to Change Behavior and Increase Sustainability in the Real World: a Systematic Review of the Literature. Sustainability. 11, 1-41.

[6] Cialdini, R. B., Trost, M. R. (1998). Social influence: Social norms, conformity, and compliance. In D. T. Gilbert, S. T. Fiske, \& G. Lindzey (Eds.), The handbook of social psychology (4th ed., Vol. 2, pp. 151- 192). Boston: McGrawHill.

[7] Power, D. J. (2007). How will Web 2.0 impact design and development of decision support systems? DSS News, 8(8). updated October 22, 2010.

[8] Appel, G., Grewal, L., Hadi, R., Stephen, A. T. (2019). The future of social media in marketing. Journal of the Academy of Marketing Science. 48, 79-95.
[9] Power, D. J., Philipps-Wren, G. (2011). Impact of Social Media and Web 2.0 on Decision-Making. Journal of Decision Systems. 20(3), 249-261.

[10] Farrow, K., Grolleau, G., Ibanez, I. (2017). Social Norms and Pro-environmental Behavior: A Review of the Evidence. Ecological Economics. 140, 1-13.

[11] Melnyk, V., Van Herpen, E., Fischer, A. R. H., Van Trijp, H. C. M. (2013). Regulatory fit effects for injunctive versus descriptive social norms: Evidence from the promotion of sustainable products. Mark Lett. 24, 191- 203.

[12] Goldstein, N. J., Cialdini, R. B., Griskevicius, V. (2008). A Room with a Viewpoint: Using Social Norms to Motivate Environmental Conservation in Hotels. Journal of Consumer Research. 35, 472-482.

[13] Wiernik, B. M., Ones, D. S., Dilchert, S. (2013). Age and environmental sustainability: a meta-analysis. Journal of Managerial Psychology. 28(7/8), 826-856.

[14] Barber, N. (2010). Green wine packaging: targeting environmental consumers. Int. J. Wine Bus. Res. 22(4), 423444 .

[15] Ru, X., Wang, S., Chen, Q., Yan, S. (2018). Exploring the interaction effects of norms and attitudes on green travel intention: An empirical study in eastern China. Journal of Cleaner Production. 197, 1317-1327.

[16] Wan, C., Shen, G. Q., Choi, S. (2017). Experiential and instrumental attitudes: Interaction effect of attitude and subjective norm on recycling intention. Journal of Environmental Psychology. 50,67-79.

[17] Marchand, A., Walker, S. (2008). Product development and responsible consumption: Designing alternatives for sustainable lifestyles. Journal of Cleaner Production. 16(11), $1163-1169$

[18] Stoll-Kleemann, S., Smidt, U. J. (2017) Reducing meat consumption in developed and transition countries to counter climate change and biodiversity loss: a review of influence factors. Reg. Environ. Change. 17, 1261-1277.

[19] Agnihotri, R., Kothandaraman, P., Kashyap, R., Singh, R. (2012). Bringing social into sales: The impact of salespeoples' social media use on service behaviors and value creation. Journal of Personal Selling \& Sales Management, 22(3), 333-348.

[20] Hagger, M. S. (2019). The reasoned action approach and the theories of reasoned action and planned behavior. In D. S. Dunn (Ed.), Oxford Bibliographies in Psychology. New York, NY: Oxford University Press.

[21] Sheppard, B.H., Hartwick, J., Warshaw, P. R. (1988). The theory of reasoned action: A meta-analysis of past research with recommendations for modifications and future research. Journal of Consumer Research. 15(3), 325-343.

[22] Fishbein, M., Ajzen, I., (1975). Belief, Attitude, Intention and Behavior: An Introduction To Theory and Research. Reading, MA: Addison-Wesley.

[23] Fishbein, M. Ajzen, I. (2010). Predicting and changing behavior: The Reasoned Action Approach. New York: Taylor \& Francis. 
[24] Vermeir, I., Verbeke, W. (2008). Sustainable food consumption among young adults in Belgium: Theory of planned behavior and the role of confidence and values. Ecological Economics. 64(3), 542-553.

[25] Ajzen I. (1991). The Theory of Planned Behavior. Organizational Behavior and Human Decision Processes. 50, 179-211.

[26] Cialdini, R. B. (2003). Crafting Normative Messages to Protect the Environment. Current Directions in Psychological Science. 12(4), 105-109.

[27] Allcott, H. (2011) Social norms and energy conservation. Journal of Public Economics. 95(9), 10821095 .

[28] Cialdini, R.B., Reno, R.R., Kallgren, C.A. (1990). A focus theory of normative conduct: recycling the concept of norms to reduce littering in public places. Journal of Personality and Social Psychology. 58, 1015-1026.

[29] Sujata, M., Khor, K., Ramayah, T. (2019). The role of social media on recycling behavior. Sustainable Production and Consumption. 20, 365-374.

[30] Young, S. D., Jordan, A. H. (2013). The Influence of Social Networking Photos on Social Norms and Sextual Health Behaviors. Cyberpsychology, Behavior and Social Networking. 16(4), 243-247.

[31] Hynes, N., Wilson, J. (2016). I do it, but don't tell anyone! Personal values, personal and social norms: Can social media play a role in changing pro-environmental behaviors? Technology Forecasting \& Social Change. 111, 349-359.

[32] Lance, H. R., Kwak, N., Shah, D. V. (2003) Environmental concern, patterns of television viewing, and pro-environmental behaviors: Integrating models of media consumption and effects. Journal of Broadcasting and Electronic Media. 47(2), 177-196.

[33] Nerb, J., Spada, H. (2001) Evaluation of environmental problems: A coherence model of cognition and emotion. Cognition and Emotion. 15(4), 521-551.

[34] Stamm, K. R., Clark, F., Reybolds Eblacas, P. (2000) Mass communication and public understanding of environmental problems: The case of global warming. Public Understanding of Science. 9(3), 219-237.

[35] Ingram, R. (2015). Exploring Emotions within Formal and Informal Forums: Messages from Social Work Practitioners. The British Journal of Social Work. 45(3), 896913.

[36] Livingstone, A. G., Haslam, A. S., Postmes, T., Jetten, J. (2011). "We Are, Therefore We Should": Evidence That InGroup Identification Mediates the Acquisition of In-Group Norms. Journal of Applied Social Psychology. 41(8), 1857-1876.

[37] Oakley, R., Salam, A. (2014) Examining the impact of computer-mediated social networks on individual consumerism environmental behaviors. Computers in Human Behavior. 35, 516-526.

[38] Winter, P. L., Cialdini, R. B., Bator, R. J., Rhoads, K., Sagarin, B. J. (1998). An analysis of normative messages in signs at recreation settings. Journal of Interpretation Research $3,39-47$.

[39] Bergquist, M., Nilsson, A. (2016). I saw the sign: Promoting energy conservation via normative prompts. Journal of Environemtnal Psychology. 46, 23-31.

[40] Gerber, P., Steinfeld, H., Henderson, B., Mottet, A., Opio, C., Dijkman, J., Falcucci, A., Tempoi, G. (2013). Tackling Climate Change Through Livestock: a Global Assessment of Emissions and Mitigation Opportunities. Food and Agriculture Organization of the United Nations. FAO, Rome.

[41] Goldstein, B., Moses, R., Sammons, N., Birkved M. (2017). Potential to Curb the Environmental Burdens of American Beef Consumption Using a Novel Plant-Based Beef Substitute. PLoS ONE. 12(12).

[42] Galanakis, C. M. (2019). Sustainable Meat Production and Processing. Academic Press. Elsevier.

[43] Melnyk, V., Van Herpen, E., Fischer, A. R. H., Van Trijp, H.C.M. (2011). To think or not to think: the effect of cognitive deliberation on the influence of injunctive versus descriptive social norms. Psychology \& Marketing. 28, 709-729.

[44] Matthies, E., Schahn, J. (2004). Umweltverhalten aus differentieller Perspektive: Diagnostik, Erklärung und Veränderung individuellen Umweltverhaltens. In: Pawlik K (ed.) Enzyklopädie der Psychologie. Band V. Theorien und Anwendungen der Differentiellen Psychologie. Göttingen: Hogrefe. 685-740.

[45] Paul, J. Modi, A., Patel, J. (2016). Predicting Green Product Consumption Using Theory of Planned Behavior and Reasoned Action. Journal of Retailing and Consumer Services. $29,123-134$.

[46] Beske, P., Land, A., Seuring, S. (2014). Production Economics Sustainable Supply Chain Management Practices and Dynamic Capabilities in the Food Industry: A Critical Analysis of the Literature. International Journal of Production Economics. 152, 131-43.

[47] Arlt, D., Hoppe, I., Wolling, J. (2011). Climate change and media usage: Effects on problem awareness and behavioral intentions. The International Communication Gazette. 73(1-2), 45-63.

[48] Mao, C., Koide, R., Brem, A., Akenji, L. (2020). Technology foresight for social good: Social implications of technological innovation by 2050 from a Global Expert Survey. Technological Forecasting and Social Change. 153, 119914

[49] Cronce, J. M., Larimer, M. E. (2013). Chapter 81Individual Prevention of College Student Alcohol Misuse. Comprehensive Addictive Behaviors and Disorders. Academic Press. 3, 803-813.

[50] Abu-Elsamen, A., Akroush, M. N., Asfour, N. A., Jabali, H. A. (2018). Understanding contextual factors affecting the adoption of energy-efficient household products in Jordan. Sustainability Accounting, Management and Policy Journal. 10(2), 314-332.

[51] Chen, M. F., Tung, P. J. (2014). Developing an extended theory of planned behavior model to predict consumers' intention to visit green hotels. International 
Journal of Hospitality Management. 36, 221-230.

[52] Melnyk, V., Van Herpen, E., Fischer, A. R. H., Van Trijp, H. C. M. (2010). The Influence of Social Norms in Consumer Decision Making: a Meta-Analysis. NA Advances in Consumer Research. 37, 463-464.

[53] Povey, R., Conner, M., Sparks, P., James, R., Shepherd, R. (2000). Application of the Theory of Planned Behavior to two dietary behaviors: Roles of perceived control and selfefficacy. British Journal of Health Psychology. 5(2), $121 \mathrm{e} 139$.

[54] Misra, S., Panda, R.K. (2017). Environmental consciousness and brand equity. An impact assessment using analytical hierarchy process (AHP). Mark. Intell. Plann. 35, 40-61.

[55] Seth, J. N., Sethia, N. K., Srinvas, S. (2011). Mindful consumption: A customer-centric approach to sustainability. J. Acad. Mark. Sci. 39, 21-39.

[56] Litt, D. M., and M. L. Stock. (2011). Adolescent alcohol-related risk cognitions: The roles of social norms and social networking sites. Psychology of Addictive Behaviors. 25(4), 708-771.

[57] Schachter, S. (1959). The psychology of affiliation: Experimental studies of the sources of gregariousness. (Vol. 1). Stanford, CA: Stanford University Press.

[58] Misra, A., Walker, M. A. (2013). Topic Independent Identification of Agreement and Disagreement in Social Media Dialogue. Association for Computational Linguistics. Metz, France, 2013. Proceedings of the SIGDIAL 2013 Conference, 41-50.

[59] De Brito Silva, M. J., Alencar De Farias, S., Kovacs Grigg, M., De Lourdes de Azevedo Barbosa, M. (2019). Online Engagement and the Role of Digital Influencers in Product Endorsement on Instagram. Journal of Relationship Marketing, 1533-2675.

[60] Wang, L., Cardie, C. (2014). Improving Agreement and Disagreement Identification in Online Discussions with A Socially-Tuned Sentiment Lexicon. Proceedings of the 5th Workshop on Computational Approaches to Subjectivity, Sentiment and Social Media Analysis. Association for Computational Linguistics, 97-106.

[61] Janoff-Bulman, R., Sheikh, S., Hepp, S. (2009). Proscriptive Versus Prescriptive Morality: Two Faces of Moral Regulation. Journal of Personality and Social Psychology. 96(3), 521-537.

[62] Zhou, Y., Moy, P. (2007). Parsing framing processes: The interplay between online public opinion and media coverage. Journal of Communication. 57, 79-98.

[63] Dunlap, R. E., Van Liere, K. D., Mertig, A. G., Jones, R. E. (2000). New Trends in MeasuringEnvironmental Attitudes: Measuring Endorsement of the New Ecological Paradigm: A Revised NEP Scale. Journal of Social Issues. 56(3), 425-442.

[64] Hawcroft, L. J., Milfont, T. L. (2010). The use (and abuse) of the new environmental paradigm scale over the last 30 years:
A meta-analysis. Journal of Environmental Psychology. 30, $143-158$.

[65] Ntanos, S., Kyriakopoulos, G., Skordoulis, M., Chalikias, M., Arabatzis, G. (2019). An Application of the New Environmental Paradigm (NEP) Scale in a Greek Context. Energies. 12(239), 1-18.

[66] Ajzen, I., Fishbein, M. (1977). Attitude-behavior relations: a theoretical analysis and review of empirical research. Psychol. Bull. 84, 888-918.

[67] Weigel, R. H. (1983). Environmental attitudes and the prediction of behavior. In Fransson, Niklas and Gorling, Tommy (1999). Environmental concern: conceptual definitions methods, and research findings. J. Environ. Psychol. 19, 369-382.

[68] Burchell, K., Rettie, R., Patel, K. (2013). Marketing social norms: Social marketing and the social norm approach. Journal of Consumer Behavior. 12, 1-9.

[69] Kallgren, C. A., Reno, R. R., Cialdini, R. B. (2000). A focus theory of normative conduct: When norms do and do not affect behavior. Personality and Social Psychology Bulletin. 26(8), 1002-1012.

[70] De Boer, J., Aiking, H. (2011). On the merits of plantbased proteins for global food security: Marrying macro and micro perspectives. Ecol. Econ. 70, 1259-1265.

[71] Sabaté, J., Soret, S. (2014). Sustainability of plant- based diets: Back to the future. Am. J. Clin. Nutr. 100, 476-482.

[72] Forwood, S. E., Ahern, A. K., Marteau, T. M., Jebb, S. A. (2015). Offering within-category food swaps to reduce energy density of food purchases: a study using an experimental online supermarket. International Journal of Behavioral Nutrition and Physical Activity. 12(1), 85.

[73] Graham, T., Abrahamse, W. (2017). Communicating the climate impacts of meat consumption: The effect of values and message framing. Global Environmental Change. 44, 98108 .

[74] Sunstein, C. R. (2019). How change happens. MIT Press.

[75] Melnyk, V., Van Herpen, E., Jak, S., Van Trijp, H. C. M. (2019). The Mechanisms of Social Norms Influence on Consumer Decision Making. Zeitschrift für Psychologie. 227(1), 4-17.

[76] Priante, A. (2019). Tweet your \#mo and save a bro: Micro-mobilization dynamics and outcomes of online social movement campaigns. Enschede: University of Twente. https://doi.org/10.3990/1.9789036547222.

[77] Caraban, A., Karapanos, E., Goncalves, D., Campos, P. (2019). 23 Ways to Nudge: A Review of TechnologyMediated Nudging in Human-Computer Interaction. CHI 2019 Paper, May 4-9, Glasgow, Scotland, UK.

Correa, T., Hinsley, A. W., de Zúñiga, H. G. (2010). Who Interacts on the Web?: The Intersection of Users' Personality and Social Media Use. Computers in Human Behavior. 26(2), $247-253$. 


\section{Appendix A}

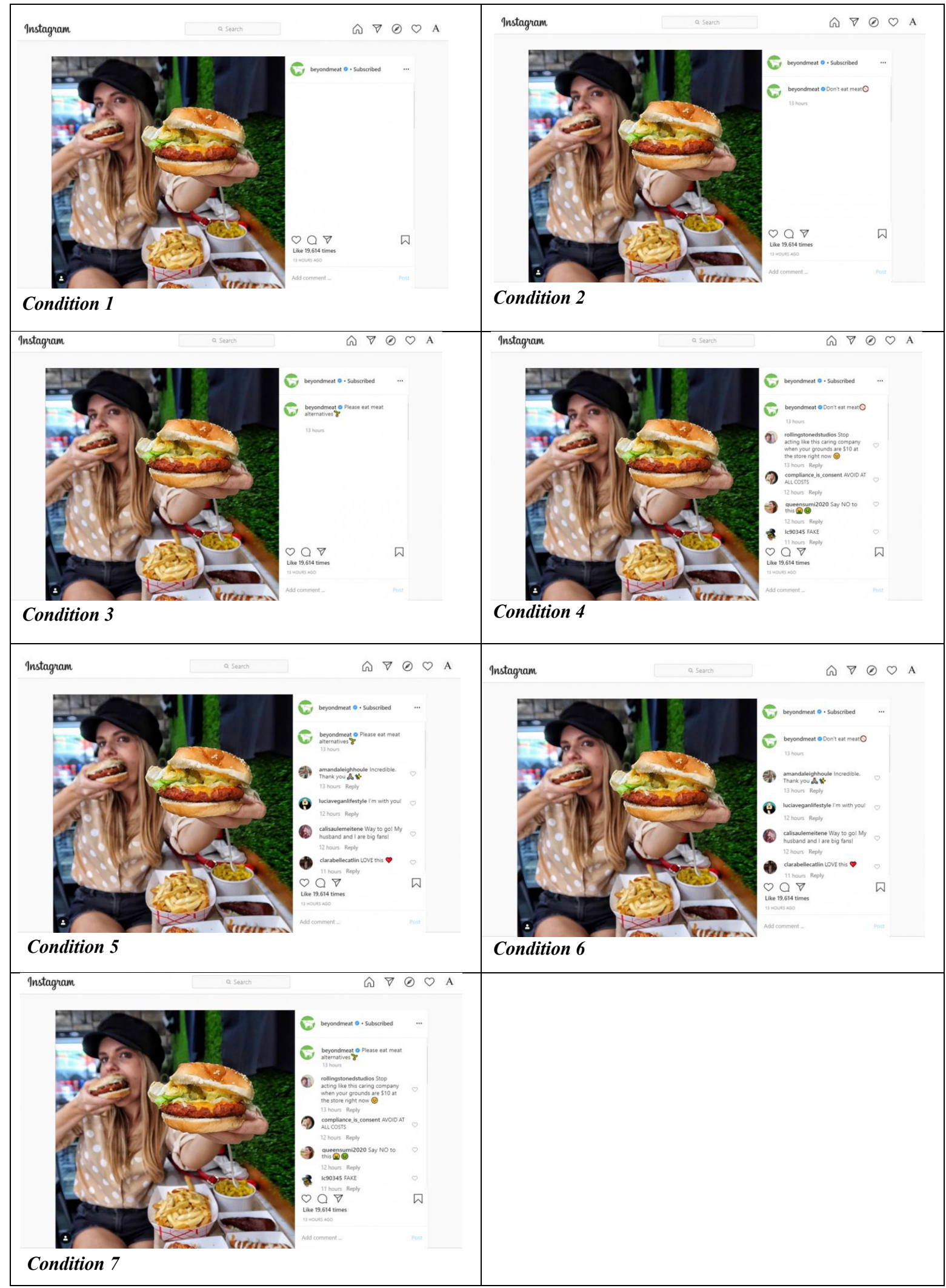

